\title{
UNEXPECTED COMPLICATIONS FOLLOWING AN OCCUPATIONAL INJURY
}

Kumara D.M.C.W. \& Kitulwatte I.D.G.

Department of Forensic Medicine, Faculty of Medicine, University of Kelaniya, Sri Lanka

\begin{abstract}
Experts in forensic medicine are often requested to give an opinion on bodily damage resulting at work. General hazards in a work environment include electricity, fire, inflammable gases, high pressure gases and liquids, powerful or sharp moving machinery and fall. When an occupational trauma is complicated with an unexpected sequelae the forensic pathologist is in a dilemma. We report a workman who was brought following blunt head and chest trauma complicated with a facial palsy and lobar pneumonia.
\end{abstract}

\section{Case study}

A 53 year old security officer was brought to the hospital following improperly fixed gate falling on to him while at work. He was recruited by the security company two months back and was appointed to this place without informing the condition of the gate. History revealed that he was unconscious for a few minutes and remained to have dizziness and vertigo. Next day he developed profound left lower motor neurone facial nerve palsy. He had fractures of the right petrous temporal bone, and a left scapula. Two weeks later he developed shortness of breath and fever, which was diagnosed as left sided lobar pneumonia.

\section{Conclusion}

Fracture of the bones and the facial nerve damage could be easily categorized as grievous injuries. Chest trauma may result in localized pulmonary contusion which can be complicated as an infection presenting late. The appreciation of the association between the infection and initial injury needs thorough scientific basis since the category of hurt is crucial in formation of medico legal opinion.

Key words: Occupational injury, medico-legal opinion, unexpected complications, facial nerve palsy, chest trauma, lobar pneumonia.

Corresponding author: drwasadissanayake@yahoo.com

\section{INTRODUCTION}

Injuries due to workplace accidents are on the rise worldwide. ${ }^{1}$ A survey done in year 2000 shows $15 \%$ of the injuries are due to occupational health hazards. ${ }^{2}$ According to the statistics of the Ministry of Health regarding occupational health, out of the fatal accidents, $30 \%$ are from construction industry and 30\% from electrocutions. Most of these hazards and accidents are preventable. $^{2}$

An injury or pathological process that affects an employee as a result of an event at work can be claimed for compensation according to international laws. ${ }^{3}$ Experts in forensic medicine are often requested to give an opinion on bodily damage resulting at work. General hazards in a work environment include electricity, fire, inflammable gases, high pressure gases and liquids, hot gases and liquids, powerful or sharp moving machinery and fall. When an occupational trauma is complicated with an unexpected sequelae the forensic pathologist is in a dilemma. We 
report a man who was brought following a blunt head and chest trauma complicated with a facial nerve palsy and lobar pneumonia as a consequence of occupational trauma.

\section{CASE STUDY}

A 53 year old security officer was brought to the hospital following an improperly fixed gate falling on to him while at work. He was recruited by the security company two months back and was appointed to this place without informing the condition of the gate. History revealed that he was unconscious for a few minutes and continued to have dizziness and vertigo. The next day, he developed profound left lower motor neurone facial nerve palsy. He was found to have fractures on the left petrous temporal bone, and left scapula. Two weeks later, he developed shortness of breath and fever which was diagnosed as left sided lobar pneumonia. Medico legal examination revealed that he was not under the influence of alcohol at the time. $\mathrm{He}$ is a chronic alcoholic and a smoker, but was previously healthy. He was reviewed on 17/12/2015, and the neurologist recommended a nerve conduction study and EMG, which indicated severe left facial nerve injury with no evidence of reinnervation and suggested nerve repair.

\section{DISCUSSION}

Anybody who faces an accident, or suffers from an injury or disease resulting in the total or partial disability of the workman for a period exceeding seven days ${ }^{3}$ due to their occupation, is eligible for compensation awards and medical care that is paid by the employer according to the workers' compensation laws of the country. The occurrence must be unexpected to be considered accidental in the context of compensation. ${ }^{4}$ However, if an injury is sustained as a result of conduct not expected from the employee, coverage under Workers' compensation will be denied. ${ }^{5}$ The fall of the gate in this case was unexpected and was accidental. This man was unaware of the fact that the gate was not fixed and he was expected to operate the gate and was not under the influence of alcohol at the time of the incident. Thus, this is a case to be considered for payment of workman's compensation.

He was given inward treatment for 34 days where his earning capacity was totally affected (temporary total disability) during the period. He had an un-displaced fracture of the left petrous temporal bone and profound facial nerve palsy of the same side on the following day. The facial nerve palsy following trauma, is uncommon which occurs in $1.5 \%$ patients of skull base fractures. ${ }^{6}$ In most of the cases, spontaneous recovery follows. However, the opinion of the neurologist in this case was that the damage will be permanent. He will most probably be left with facial nerve damage resulting in paralysis of facial muscles and loss of sensation of anterior $2 / 3$ of the tongue and loss of secret motor functions of the submandibular, sublingual and lacrimal glands. Complications of Bell's palsy include disfigurement or permanent contracture from irreversible facial nerve damage, eye damage (corneal ulcers and infections), chronic spasm of facial muscles and/or eyelids, and chronic taste abnormalities. Involuntary contraction of certain muscles may result from misdirected re-growth of nerve fibers. Psychological trauma may accompany facial disfigurement in some individuals. ${ }^{7}$ The onset of facial nerve palsy may be immediate or delayed. Delayed facial nerve paralysis occurs usually after 1-10 days of trauma and commonly due to entrapment of nerves within the fibrous tissue or oedema, and chances of recovery are high. Immediate facial nerve palsy occurs due to stretching/compressing/crushing the part of the nerve, where recovery chances are low and late. ${ }^{8}$ The facial nerve paralysis was observed in this man on the following day. However, before a conclusion is made regarding whether the damages are permanent, it is important to review him since there are some patients who had fully recovered after 6 months. ${ }^{9}$ The Workman Compensation Act of Sri Lanka includes 
severe facial scarring or disfigurement as $75 \%$, permanent total loss of vision as $50 \%$ and total loss of taste as $25 \%$ to loss of earning capacity. ${ }^{3}$

On the other hand, criminal negligence causing bodily harm is an indictable offence. In this case, the hospital authority is responsible for recklessly employing this man at this unfixed gate without ensuring his safety. Thus, forensic medical examination is required in categorizing the bodily harm or hurt. Fracture of the bones and facial nerve damage could be easily categorized as grievous injuries under limbs ' $\mathrm{g}$ ' and ' $\mathrm{f}$ ' of the section 311 of the penal code. ${ }^{10}$

This man developed a lobar pneumonia while being managed for the fractures in the ward. The appreciation of the association between the infection and initial injury needs scientific basis before concluding the category of hurt. Chest trauma, specially the fracture of the scapula, can result in contusion of the adjacent lung. It takes an average of six hours for the characteristic white region to show up on a chest X-ray, and sometimes contusion may not become apparent for 48 hours. $^{11}$ The initial chest Xray of this man did not show any pulmonary contusions and further $\mathrm{X}$ - rays were not taken until he developed pneumonia in two weeks. However, considering the extent of the fracture, it is highly likely for him to get contusions of the adjacent lung.

Pulmonary contusion is associated with complications including pneumonia ${ }^{12}$ and acute respiratory distress syndrome, and it can cause long-term respiratory disability. As many as $20 \%$ of people with pulmonary contusion develop pneumonia. ${ }^{13}$ Infection that occurs within 72 to 96 hours of injury is termed 'early onset pneumonia'. Both early onset as well as late onset pneumonias (as in our case) are reported following pulmonary contusions. ${ }^{14}$ The risk of pneumonia in lung contusion begins almost immediately after acute traumatic damage. Both gram-positive and gram-negative bacteria are responsible for pneumonia in trauma patients. However, a late onset pneumonia has an equal mix of gram-positive and gram-negative bacteria as the offending microbe that is isolated on the culture. ${ }^{15}$ Contused lungs are a good culture media for growth of bacteria. Contusions induce inflammation with high local concentrations of pro-inflammatory mediators stimulating chemotaxis and activation of neutrophils. ${ }^{16}$ Further, impaired chest movements, and cough reflex also predispose the infection. In patients with trauma, significant risk factors for pneumonia include age, gender, pulse rate, systolic blood pressure, obesity, Glasgow Coma Scale motor score and ventilation on admission. ${ }^{17}$

The pneumonia in this man was a left lower lobar pneumonia which was developed two weeks after the chest trauma. By definition, this can also be considered as a nosocomial or hospital acquired pneumonia, which is contracted by a patient in a hospital at least 48-72 hours after being admitted. It is usually caused by bacterial infections. Common risk factors include, mechanical ventilation, old age, decreased filtration of inspired air, disease states that result in respiratory tract obstruction, trauma, (abdominal) surgery, medications, diminished lung volumes or decreased clearance of secretions. However, the pneumonia in this man was a left lower lobar pneumonia which is the area that could have been badly affected by the trauma on the lower scapular area suggesting the relationship to the trauma.

In addition to the chest trauma, this 53 year old man had other risk factors to develop pneumonia which include chronic smoking and chronic alcoholism leading to chronic pulmonary damage and consequently immune suppression. However, this man was previously healthy and acquired all these complications following the traumatic event.

Lobar pneumonia needs proper anti-bacterial therapy. The mortality rate of hospital acquired pneumonia remains high at $30 \%$ even with treatment. ${ }^{18}$ This indicates the seriousness of the condition. However, since the condition is a remote complication of the 
initial trauma and it is contributed by his existing weaknesses, the category of hurt was concluded as endangering life.

\section{CONCLUSIONS}

This man was an unfortunate victim of blunt force trauma associated with two uncommon complications following an accident at the work place. The case highlights the importance of proper scientific investigations considering the differential diagnosis in establishing the causal relationship in remote complications associated with medico legal trauma in proper administration of justice.
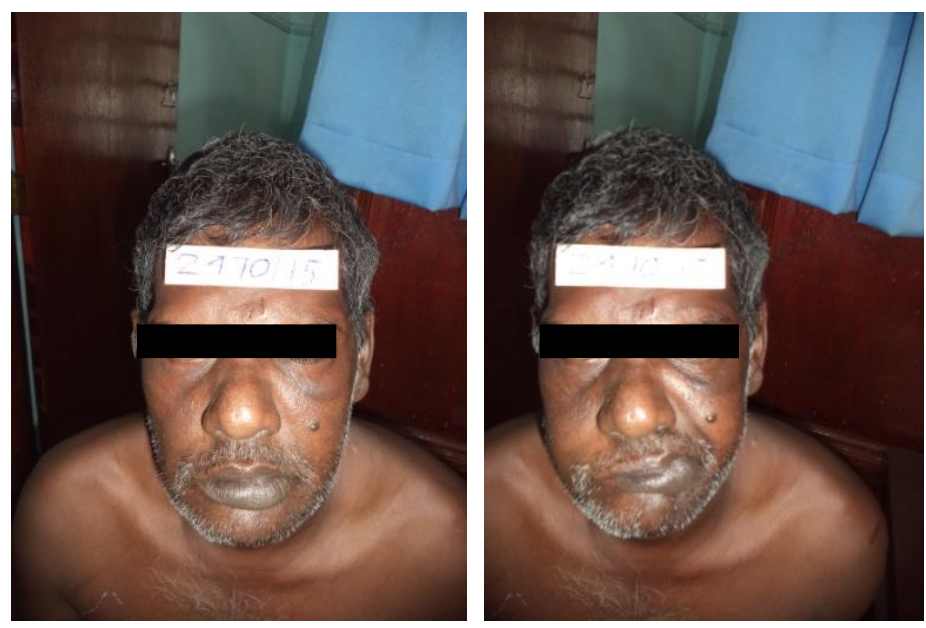

Lower motor facial nerve palsy

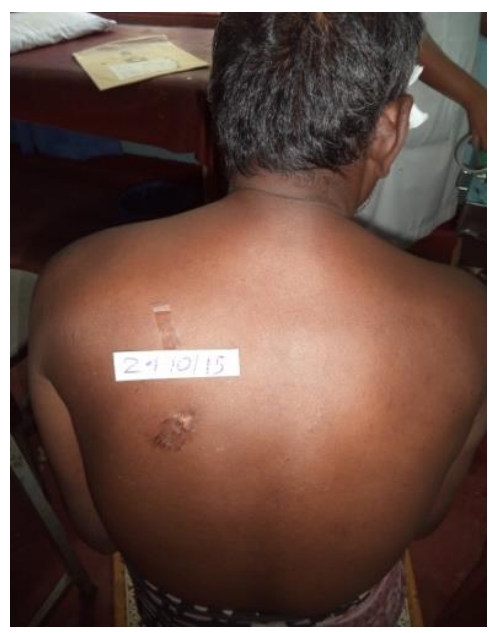

Abrasion on the back of the chest

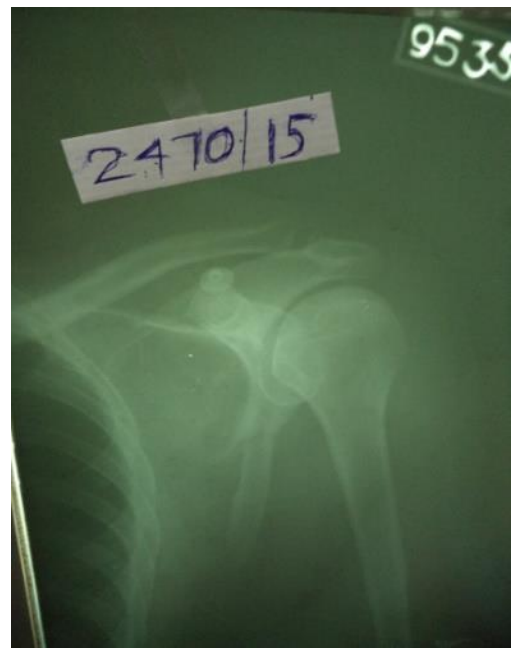

Left scapular fracture

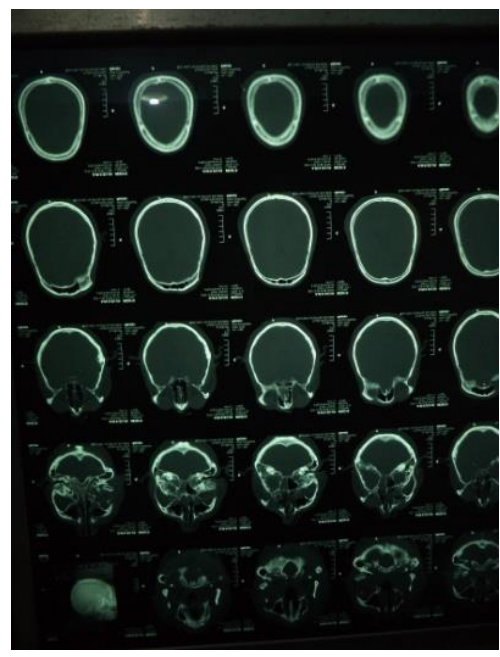

CT scan showing petrouse temporal bone fracture

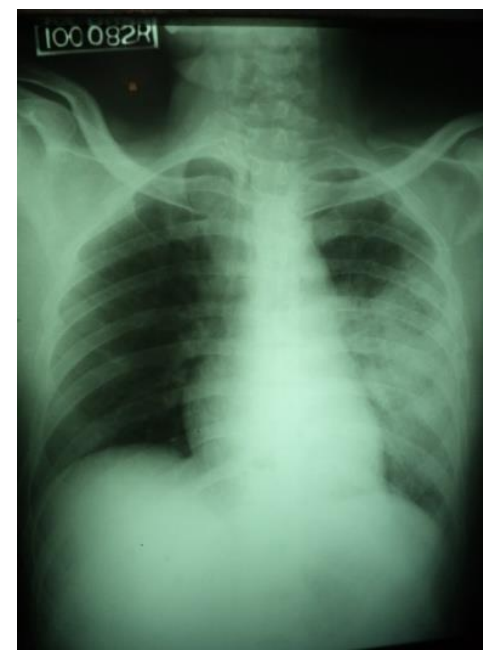

CXR showing left lobar pneumonia 


\section{REFERENCES}

1. Statistics of occupational injuries. Sixteenth International Conference of Labour Statisticians. Geneva. 6-15 October 1998. International Labour Organization.

2. www.health.gov.lk OccupationalHealth

3. Workmen's Compensation ordinance. Vol. viii. Laws of Sri Lanka. www.srilankalaw.lk/...VIII/workmen-scompensation-ordinance.html

4. Accidental injury under the New York Workmen's Compensation Law. 28 Fordham L. Rev. 322 (1959)

5. Thomas D. Terry, Workmen's Compensation - Statutory Requirement of Injury by Accident, 2 Wm. \&Mary L. Rev. 289 (1959), vol2,iss 1, 144

6. PP Devriese. Facial paralysis after trauma of the skull. In, Samii M and Brihaye J (eds). Traumatology of the skull base.Springer Verlag New York 1983:155-63

7. Bell's Palsy." MayoClinic.com. 24 Sep. 2004. Mayo Foundation for Medical Education and Research. 1 Jul. 2009 <http://www.mayoclinic.com/invoke.cfm?o bjectid=2B73952A-337E-4AB795368E5C254B2D65\&dsection $=1$

8. K. Puvanendran, M.Vitharana and P. K.Wong. Delayed facial palsy after head injury Journal of Neurology, Neurosurgery and Psychiatry. 1977. 40; 342-350

9. Keki E Turel, Nootan Kumar Sharma, Joy Verghese, Sanjeev Desai. Post Traumatic Facial ParalysisTreatment Options and Strategies. Indian Journal of Neurotrauma (IJNT) 2005, Vol. 2, No. 1, pp. 33-34

10. Legislative enactment of Ceylon. Penal Code [Sri Lanka], Ch; 19 Section 311
11. Wanek S, Mayberry JC. Blunt thoracic trauma: Flail chest, pulmonary contusion, and blast injury. Crit Care Clin 2004;20(1):71-81.,Allen GS, Coates NE. Pulmonary contusion: A collective review. Am Surg 1996;62(11):895-900.

12. Croce MA, Fabian TC, Waddle-Smith L, Maxwell RA. Identification of early predictors for post-traumatic pneumonia. Am Surg 2001; 67:105-10

13. Tovar JA. "The lung and pediatric trauma". Seminars in Pediatric Surgery (2008)17 (1): 53-59. doi:10.1053/j.sempedsurg.2007.10.008.

14. Hafen GM, Massie J. Lung contusion from focal low-moderate chest trauma Pediatr Pulmonol. 2006 Oct;41(10):1005-7

15. Dolgachev VA, Yu B, Reinke JM, Raghavendran K, Hemmila MR. Host susceptibility to gram-negative pneumonia after lung contusion. The journal of trauma and acute care surgery. 2012;72(3):614-623. doi:10.1097/TA.0b013e318243d9b1.

16. Vladislav A. Dolgachev, Julia M. Reinke, Krishnan Raghavendran, R. Hemmila,Host susceptibility to gram-negative pneumonia after lung contusion. J Trauma Acute Care Surg. 2012 Mar; 72(3): 614-623.doi: 10.1097/TA.0b013e318243d9b1

17. Janus TJ, Vaughan-Sarrazin MS, Baker LJ, Smith HL.Predictors of pneumonia in trauma patients with pulmonary contusion.J Trauma Nurs. 2012 Jul-Sep;19(3):139-47. doi: 10.1097/JTN.0b013e318261d1e2.

18. Crouch Brewer S, Jones CB, Leeper KV, Wunderink RG. Ventilator-associated pneumonia due to Pseudomonas aeruginosa. Chest 1996;109:1029 